\title{
EPONYMS IN HERNIA SURGERY
}

Sayantan Bose1, Ramanuj Mukherjee², Shreya Sengupta ${ }^{3}$, Gouri Mukhopdhyay ${ }^{4}$

${ }_{1}^{1}$ M.B.B.S, Department of Surgery, R. G. Kar Medical College, Kolkata.

${ }_{2}^{2}$ M.S., Department of Surgery, R. G. Kar Medical College, Kolkata.

${ }^{3}$ M.B.B.S, Department of Surgery, R. G. Kar Medical College, Kolkata.

${ }^{4}$ Postgraduate Student (M.S.), Department of Surgery, I.P.G.M.E.R, Kolkata

\section{ABSTRACT}

\section{BACKGROUND}

The saying goes "The history of hernia repair is the history of surgery". The history of open surgery for groin hernia has gone through many stages of development starting from the Romans, Greeks and the Egyptians. Starting from the use of trusses, taxis for strangulation and routine excision of the genitals came the dark middle Ages, which have been described by historians as a period of surgery in eclipse and centuries of ignorance. During Renaissance, new surgical knowledge flourished and the foundation of herniology was begun. Hernia surgery saw an upstroke in late $19^{\text {th }}$ century with initial description by Marcy and Bassini. The following article is a historical recollection on the various controversies, incidents and achievements in world of hernia.

\section{KEYWORDS}

Eponyms, Bassini, Marcy, Shouldice, Stoppa, McVay, Lichtenstein, Gilbert, Laparoscopic Hernia Surgery, History of Hernia Surgery.

HOW TO CITE THIS ARTICLE: Bose S, Mukherjee R, Sengupta S, et al. Eponyms in hernia surgery. J. Evolution Med. Dent. Sci. 2017;6(57):4272-4275, DOI: 10.14260/Jemds/2017/925

\section{BACKGROUND}

The saying goes "The history of hernia repair is the history of surgery". The history of open surgery for groin hernia has gone through many stages of development starting from the Romans, Greeks and the Egyptians. Starting from the use of trusses, taxis for strangulation and routine excision of the genitals came the dark middle Ages, which have been described by historians as a period of surgery in eclipse and centuries of ignorance. During Renaissance, new surgical knowledge flourished and the foundation of herniology was begun. Hernia surgery saw an upstroke in late $19^{\text {th }}$ century with initial description by Marcy and Bassini. The following article is a historical recollection on the various controversies, incidents and achievements in world of hernia.

\section{Marcy Versus Bassini- Who is better?}

Dr. Henry O. Marcy, born in Massachusetts in 1837, was a graduate of Amherst College and Harvard Medical School and received his M.D. degree in 1864. He served with the Union Armies during the closing phase of the Civil War following which he entered the practice of medicine in Boston and later became the first American pupil of Lister whose methods he later practised and spread on returning to his country. $\mathrm{He}$ was the first to use sterilised absorbable suture material in the repair of inguinal hernia and used kangaroo tendon as the preferred source of animal sutures. His first herniorrhaphy by his new method was performed in 1871. Marcy, in 1881, was the first to advocate high ligation of the sac, transplantation of the cord, and reconstruction of the inguinal canal, as they are practised today. For the most part, he has been largely neglected, and his role has not been mentioned in the development of modern hernia surgery.

Financial or Other, Competing Interest: None.

Submission 12-06-2017, Peer Review 05-07-2017,

Acceptance 12-07-2017, Published 17-07-2017.

Corresponding Author:

Sayantan Bose,

P. K. Bose Sarani.

Hridaypur, Kolkata-700127.

E-mail: bosesayantan0@gmail.com

DOI: $10.14260 /$ jemds $/ 2017 / 925$
Marcy once said that while he was reading his papers about his surgery he saw Bassini in the audience, listening to him intently.[1] So the controversy goes on, one group claiming that what Bassini did was only adoption of the original method described by Marcy, and that he is the real father of modern herniology. Halsted even wrote "Bassini was first. Marcy never accepted Bassini's priority and laboured with the help of friends to alter the history of this event, but to no avail."'[2]

Dr. Eduardo Bassini, also called the father of modern hernia surgery, was a contemporary of Marcy. He was the son of a farmer. After studying medicine at the University of Pavia, graduating in 1866, at the age of only 22 years, he joined the Prussian-Austrian war as a foot soldier. During the war he got trauma in his abdomen and got faecal fistula which was cured by Dr. Luigi Porta who later became his great mentor. At the suggestion of his mentor, Bassini went abroad where he received training under many Greats of that time. Later he got posts as head of the Department of Surgery at the hospital La Spezia, lecturer in surgery at Parma, head of Surgical Pathology of University of Pavia. Bassini introduced Listerian techniques of antisepsis into Italian surgery. During 1883 he tried the different methods of hernia correction, most of which resulted into early recurrence and eventual use of truss. He thought this to be due to inadequacy of only ligating the sac without any canal reconstruction, because of which in 1884, he introduced a new surgical technique for hernia repair that reinforces and reconstructs the inguinal canal in a physiological way. The natural curtain mechanism of the inguinal canal is recreated and the hernia sac is ligated higher up. In 1894 he presented the results of 206 operations with an almost $100 \%$ five-year followup. [3] There were no mortalities and only eleven wound infections and 8 relapse cases. [3] Once Bassini, to check the strength of his new repair technique, instructed his assistant to introduce a feather into his patient's throat to make him cough vigorously. To much surprise, the abdominal wall remained taut and tight until the coughing ceased. ${ }^{[4]}$ Bassini's greatness must not be limited to his inguinal hernia repair technique; he also proposed other important surgical techniques such as nephropexy, subtotal hysterectomy, ileocolostomy, the cravat incision of the neck 
for thyroid operations (usually called a Kocher incision), suprapubic cystostomy, hip disarticulation, intrascapularthoracic amputation, and the technique for femoral hernia repair.

\section{Halsted's Technique}

Dr. William Stewart Halsted, was an American surgeon, born in 1852 and one the four founding professors at the Johns Hopkins Hospital. After graduating from Columbia University College of Physicians and Surgeons in 1877 as a Doctor of Medicine, he joined the New York Hospital as house physician. There he introduced the hospital chart which tracks the patient's temperature, pulse and respiration. In 1882 , he performed one of the first gallbladder operations in the United States, a cholecystotomy performed on his mother on the kitchen table at 2 a.m. Halsted also performed one of the first blood transfusions in the United States, on his sister after she had given birth. He found her moribund from blood loss, and in a bold move withdrew his own blood, transfused his blood into his sister and then operated on her to save her life. In 1884, Halsted read a report by the Austrian ophthalmologist Karl Koller, describing the anaesthetic power of cocaine when instilled on eye. Halsted experimented on himself and demonstrated that cocaine could produce safe and effective local anaesthesia when applied topically and when injected. In the process, Halsted became addicted to the drug. In an attempt to de-addict him from cocaine, morphine was used, to which he got addicted in the process. Although he remained dependent upon morphine for the remainder of his life, he continued his career as a pioneering surgeon. Along with William Osler (Professor of Medicine), Howard Atwood Kelly (Professor of Gynaecology) and William H. Welch (Professor of Pathology), Halsted (commonly called the "Big Four") were the founding professors at the Johns Hopkins Hospital, which was started in 1889. He introduced the basic principles of tissue handling which is now known as Halsted's principles. He played a major role in introducing use of latex gloves during surgery. In 1882, Halsted performed the first radical mastectomy for breast cancer in the U.S., which was a lifesaving treatment procedure for the disease with an astonishingly low recurrence rate of $6 \%$. He modified the original Bassini's technique of hernia repair by repairing the external oblique aponeurosis beneath the spermatic cord. According to the positioning of spermatic cord, Halsted did two types of herniorrhaphy - Halsted I, the cord is under the skin and in Halsted II it is under the repair. ${ }^{[4]}$ His other achievements included advances in thyroid, biliary tract, intestinal and arterial aneurysm surgery. He died in 1922 due to bronchopneumonia as a complication of surgery for gallstones and cholangitis at his 69 years of age.

\section{The Post-Renaissance Period \\ Shouldice Repair-}

Dr. Edward Earle Shouldice was a Canadian surgeon, born in 1890. His work focuses on hernia and its surgeries. During World War II, he was called to serve on the Medical Examining Board. Dr. Shouldice, a major in the army, found that many young men willing to serve their country had to be denied enlistment and needed surgical treatment to repair their hernias before they could be pronounced physically fit for military training. He performed an innovative method of surgery on seventy of these men. His unique repair method improved surgical results and reduced recovery time, quickly restoring the young recruits to physical fitness for military training. As news of Dr. Shouldice's success spread, there was a growing demand for hernia surgery. Dr. Shouldice opened his own hospital with a single operating room and a waiting list of 300 eager patients working with only a nurse, secretary and cook for support and Dr. Shouldice repaired two hernias a day. Requests for his remarkable surgery grew and the hospital soon expanded. Shouldice technique of suture based tension repair has a rate of $1 \%$ recurrence.

\section{McVay's Repair}

Dr. Chester Bidwell McVay was born in Yankton, South Dakota, in 1911, and graduated from Yankton College in 1933. McVay then went to North-western University in Chicago, and he qualified both M.D. and Ph.D. While at Northwestern, he did his research in the anatomy laboratory, where he concentrated his studies on the anatomy of the abdominal wall and the inguinal and femoral regions. He modified the original Bassini's technique by using Cooper's ligament for repairing, which was actually developed by Georg Lotheissen in 1898 and popularised by McVay.[1] McVay and Anson pointed out in 1940 that the rectus fascia, a portion of the transversalis fascia that inserts into the lateral border of the rectus muscle underneath the transversus abdominis aponeurosis, is strong enough to prevent subsequent incisional herniation (Spigelian). McVay's repair involves giving interrupted sutures from pubic tubercle to Cooper's ligament laterally instead of inguinal ligament. Due to greater recurrence, this technique is seldom used now. But for large femoral hernias, this technique has got some benefits.[5]

\section{The Beginning of Era of Mesh Repair Lichtenstein's Repair}

Dr. Irving Lester Lichtenstein was an American surgeon, born in 1920. He studied medicine at the University of Pennsylvania as well as the Hahnemann Medical College. He was the pioneer in developing the tension-free mesh repair of hernia (hernioplasty) which is still being used till current day. It can be performed on an outpatient basis and leads to significantly shorter rehabilitation and disability periods compared to other techniques. Dr. Lichtenstein, who was long active in the American Civil Liberties Union of Southern California, also loved a good battle, and he got one when he stood in front of a thousand doctors attending an American Medical Association meeting in San Francisco in 1964 and told them they were handling hernia patients all wrong.[6] The practice during those days, was to use general anaesthesia for hernia repair and to prevent the patients to work for 2 months thinking that any strain would make the repair weak and lead to recurrence.[6] Dr. Lichtenstein opposed to this, after several observations and experiments on animals he concluded that a properly sutured tear immediately regained 70 percent of its strength, and that what mattered most was how it was sewn up and what material was used.[6] To test his ideas on humans, he settled on hernia patients, since their injuries were generally confined to the tear itself. He used local instead of general anaesthesia so that the patients would be able to follow his instructions on the table; he would have them cough, for 
example, to test the strength of the repair.[6] In February 1989, Lichtenstein and associates reported on 1000 consecutive patients with primary repair of inguinal hernia using a "tension-free" repair employing a Marlex mesh prosthesis to bridge the direct floor of the groin without approximating the tissue defect. The mesh is sutured to the inguinal ligament laterally and to the rectus sheath and "conjoint tendon" above.[6] A slit is fashioned in the lateral end of the mesh to fit around the emerging cord. The "tails" of the slit are overlapped around the cord structures at the deep ring. Although Dr. Lichtenstein reported high success rates, it took years for his practices to be widely adopted. He worked to refine the surgery, devising simpler suture techniques and using mesh screens to reduce the risk of the hernia's recurring. He didn't operate for the last 18 years of his life due to Parkinson's disease, and succumbed to it at the age of 80 .

\section{Stoppa's Repair}

Professor René Stoppa was born in Constantinois in 1921. He started his medical studies at the University of Algiers' Faculty of Medicine. After World War 2, in which he was enlisted as a volunteer, he became an Assistant in Anatomy and then a demonstrator in the Anatomy Laboratory of the University of Algiers 1947 to 1954. Among the topics which caught his attention and which fostered research projects, teaching and publications are wound healing, limb ischaemia, trauma in general and multiple trauma and chronic osteomyelitis. In gastrointestinal surgery, he was interested in megacolon, peptic ulceration and gastro-oesophageal reflux. Several innovations were proposed in pancreaticobiliary surgery-sphincterotomy (Oddi), biliary tree drainage, and common bile duct replacement. In hernia surgery, he conducted research projects on prosthetic materials for abdominal wall repair, the mechanism of hernia formation, and classification of groin hernias. In 1965, he designed a technique in groin hernia repair-wrapping of the hernial sac with a large synthetic sheet through a midline pre-peritoneal approach applicable to multiple recurrent groin hernias and incisional hernias. Stoppa and colleagues first described their use of a large, unsutured Dacron prosthesis for repair of difficult groin hernias using a preperitoneal approach via a low midline incision in 1975. They chose a Dacron patch because of its adaptability, pliability, and tolerance in tissues and to infection. They used a patch that was six to ten times larger than the area of the hernia defect and simply placed the mesh in the preperitoneal space, relying on initial fixation by intraabdominal pressure on the muscular layers and later fixation by tissue adhesion and in-growth into the prosthesis.

\section{Where to Place the Mesh?}

Dr. Arthur I. Gilbert, M.D., surgeon emeritus of The Hernia Institute of Florida, founded the Institute in the 1985, and was the Director and Chief of Surgery until 2002. He received his Medical Degree from the University of Miami School of Medicine. Dr. Gilbert travelled to many places such as Padua in Italy to review historical concepts on the anatomy and repair of hernias. He searched the literature and studied the early anatomical descriptions of Henri Fruchaud. He also travelled to Toronto, Canada to study the Shouldice procedure. He solicited the opinions of many world- renowned surgeons, and organised the first "International Hernia Congress" held in Miami in 1983. In 1998, the invited surgeons subsequently formed the American Hernia Society, modelled after the European Hernia Society. Dr. Gilbert was a founding member and the first president. Dr. Gilbert's studies led him to advances in the technique of hernia repair. Realising that suture repairs had an unacceptably high rate of recurrence of 10 to 20 percent, he began studying mesh repair techniques using a tension-free concept as recommended by his close friend and colleague, Dr. Irving Lichtenstein. This dramatically reduced recurrence rates to less than five percent, but he was determined to further improve outcomes. In 1997, he proposed the concept of placing mesh both behind and in front of the hernia opening. He designed the Prolene Hernia System, a bilayer connected device. He is currently retired from the active practice of surgery, but continues to advance the teaching of Herniology by lecturing, writing articles, and moderating podcasts on the Internet. Dr. Gilbert has been the recipient of many honours and awards during his career, including the First Distinguished Service Award from the American Hernia Society, and remains a world renowned herniologist.

\section{Introduction of Modern Technology}

With the advent of computer chip technology, that allowed the magnification and projection of images onto television screens, laparoscopic visualisation and treatment of inguinal hernia got introduced in the surgical arena.[7] Dr. Ralph Ger was the first in 1982 to report a transabdominal closure of an inguinal hernia defect during a laparoscopy for other reasons. ${ }^{[8]}$ In 1989, gynaecologist S. Bogojavalensky[9] showed a video demonstrating the laparoscopic intraabdominal incision of the peritoneal hernia sac, subsequently closing the visible muscular defect with a rolled-up piece of polypropylene mesh. The early 1990s saw a rapid rise of the number of publications, confirming the feasibility of laparoscopic hernia repair.[10] A first attempt was made by applying a synthetic mesh to the peritoneal defective wall which was called IPOM (Intraperitoneal onlay mesh). Another approach (Transabdominal preperitoneal approach or TAPP) consisted in making an intraperitoneal U-type incision in the peritoneal wall and inserting the mesh in a preperitoneal position. Soon other surgeons proposed a complete extraperitoneal insertion of the preperitoneal mesh.[11] It became known as the TEP technique (Total extraperitoneal approach).

\section{No Mesh Repair !!}

Dr. Mohan Phulchand Desarda is the Professor of Surgery and Division Head of the "Hernia Centre" at Poona Hospital \& Research Centre and the Chairman of Indian Hernia Institute. He completed his bachelor's degree from BJ Medical School and got MS degree from the University of Pune (1964-1972). His academic career was extraordinary as evident by his numerous achievements viz. i. National Scholar, ii. Gold Medal in Anatomy, iii. First in University in Ist MBBS, iv. Second in University in IInd MBBS, v. First in University in Forensic Medicine, vi. Best All-Round College Student Award, vii. "Gaurav Patra" by Pune Municipal Corporation, viii. 'Doctor of the year' award in 2005 from Pune district MEDIJAIN, ix. Appointed on "International reviewer's Board" (17 countries including USA), x. Award \& gold medal from World congress 
of Medicina Alternativa. His primary interest is in research and development in different types of external hernias whereas his next field of expertisation is Gastroenterology followed by Yoga! His hernia operation technique is now called as "Dr. Desarda Repair". This technique is included in medical text books of international repute like "Bailey \& Love" and "Schwartz". His operation technique is followed in more than 65 centres now all around the globe. He has been awarded many honours by medical institutions, social, political and government organisations. Desarda repair is a simple tension-free and mesh-free herniorrhaphy (hernia repair) done under local anaesthesia without mesh, with a one night stay in hospital, minimal postoperative pain, and a quick recovery that allows you to drive your car and be back at work in Couple of Days depending on your tolerance. There is virtually a zero \% recurrence rate with minimal or negligible postoperative, early or late complications. Laparoscope is neither used nor required in this procedure. The Desarda technique of inguinal hernia repair uses live muscle tissue adjacent to the hernia site to repair and reinforce the weakened area. This new technique was demonstrated at major international Hernia Conferences to many surgeons from India as well as abroad. This is a pure tissue repair that resembles the Lichtenstein mesh repair in its simplicity. The author claims results that are superior or equal to Shouldice and Lichtenstein repairs in low frequency of complications and most importantly no recurrences. The external oblique is incised similarly to the way it is done in the other anterior approach repairs. The spermatic cord is dissected free the same way it is done in all the other anterior approach repairs. The sac are dissected free as usual and generally cut away. The herniated organs are returned to the abdomen as usual. The new lower edge of the upper flap is sutured to the original upper edge of the lower flap, above the spermatic cord -- that is, the external oblique is closed similarly to the way it is closed in Bassini, McVay, and Shouldice repairs. However, it is the newly created lower edge of the upper flap that is being used, instead of its original upper edge; the original lower edge of the upper flap has previously been sutured to the inguinal ligament. Thus, when the operation is completed, there are 2 layers of external oblique: one under the cord and one above it, instead of only one layer, below the cord, as in normal anatomy, and as in Bassini, McVay, and Shouldice repairs.

\section{REFERENCES}

[1] Patino JF. A history of the treatment of hernia. In: Fitzgibbons RJ, Greenberg AG. eds. Nyhus and Condon's hernia. $5^{\text {th }}$ edn. Philadelphia: Lippincott Williams \& Wilkins 2002:17-28.

[2] Halsted WS. The cure of the more difficult and the simpler inguinal ruptures. Johns Hopkins Hosp Bulletin: Lord Baltimore 1903;14:208.

[3] Bassini E. Who named it? http://www.whonamedit.com/doctor.cfm/3213.html.

[4] Sandalwood JE, Colborn GL. Historic aspects of chronic hernia repair. In: Fitzgibbons RJ, Greenberg AG. eds. Nyhus and Condon's hernia. $5^{\text {th }}$ edn. Philadelphia: Lippincott Williams \& Wilkins 2002:29-43.

[5] Fitzgibbons RF, Richards AT, Quinn TH. Open hernia repair. In: Saube WW, Fink MP. eds. ACS Surgery: Principle and practice. $6^{\text {th }}$ edn. Chicago: BC Decker 2007:828-49.

[6] Nagourney E, Lichtenstein I. Pioneer in Hernia Surgery, Dies at 80. The New York Times. 2000.

[7] Schultz L, Graber J, Pietrafitta J, et al. Laser laparoscopic herniorrhaphy: a clinical trialpreliminary results. J Laparosc Surg 1990;1:41-5.

[8] Shearburn EW, Myers RN. Shouldice repair for inguinal hernia. Surgery 1969;66(2):450-9.

[9] Simons MP, de Lange D, Beets GL, et al. Richtlijn 'Liesbreuk' van de Nederlandse Vereniging voor Heelkunde. Ned Tijdschr Geneeskd 2003;147(43):2111-7.

[10] Simons MP, Aufenacker T, Bay-Nielsen M, et al. European Hernia Society guidelines on the treatment of inguinal hernia in adult patients. Hernia 2009;13(4):343-403.

[11] Stoppa RE, Rives JL, Warlaumont CR, et al. The use of Dacron in the repair of hernias of the groin. Surg Clin N Am 1984;64(2):269-85. 